\title{
Cultural conditionality of understanding in social hermeneutics
}

\author{
Liudmila Pazina* \\ Don State Technical University, 344006, Rostov-on-Don, Russia
}

\begin{abstract}
Social hermeneutics is a young, emerging branch of philosophy associated with problems of understanding social actions. Since any social action is aimed at transforming the human world, our present, future and past, understanding its motives and goals is of practical importance for each person and humanity as a whole. A social action always has a cultural-historical context. Understanding the motive and the meaning of the social action is impossible outside the language system that determines it and the culture of a particular nation.
\end{abstract}

\section{Introduction}

In a broad sense, hermeneutics considers understanding as a condition for comprehension and interpretation of social being. It could not find its place in the social sciences for a long time, and disputes as to whether the social sciences should deal with hermeneutical dimensions of research have begun in the 60 s of the 20th century and are still going. Social hermeneutics as a branch has not been sufficiently developed and theoretically substantiated yet, but it is actively developing, relying on the understanding sociology of M. Weber and the phenomenological sociology of A. Schutz. The study of problems of social hermeneutics is based also on the works of M. Heidegger, H.-G. Gadamer, M. Bakhtin, Z. Bauman, W. Dilthey, T. Parsons, F. Schleiermacher and others. Views on the purpose and status of social hermeneutics continue to be dynamically transformed in modern philosophy.

Hermeneutical procedures are always social, because the issues of understanding and interpretation are always socially and culturally determined. However, in contrast to classical hermeneutics as a theory and practice of interpretation of texts that gradually gains an ontological dimension, the original task of social hermeneutics was to understand subjective motives, goals and meanings of persons by their social actions. The problem of understanding, which is the central one for social hermeneutics, combines it with the general philosophical hermeneutics as a method and a branch. However, the problems of understanding the social action itself as a procedural act (what is being done?), as well as the results of this action in a sociocultural context (how and for what?), and the problems of understanding hidden and explicit motives (what causes this social action?), goals (why?) and meanings of actors of the social action have their own peculiarity in social

*Corresponding author: leroshenko@mail.ru 
hermeneutics. This peculiarity is associated with the dynamism of the social action itself in a society permeated with meanings, interwoven into a cultural-historical context. Its cultural conditionality is of particular importance for understanding the motive and the meaning of the social action.

Understanding the meaning of the social action is an important theoretical and practical task. Unlike an action in general that aims at any changes, a social action is aimed at transforming the human world, our reality, including the present, the past and the future.

Any social activity of a person, his/her social action is determined by the cultural context. In order to understand the meaning of a social action, it is necessary to take into account the cultural conditionality of an actor and an interpreter of this action. Understanding the meanings that persons put into their actions is the basis both for the successful existence of a specific person and for the existence of the world as a whole.

\section{Research Method}

The general task of social hermeneutics is to understand a social action of a person. The cultural conditionality of an actor of a social action and an interpreter in understanding a social action requires using techniques of modern rationalistic methodology and methods of historical and cultural hermeneutical reconstruction.

Moreover, the transition from methodological holism to methodological individualism characteristic of modern post-non-classical rationality is also characteristic of social hermeneutics. Methodological individualism is typical in determining the motives of the social action of a person.

Considerable importance in the methodology of social hermeneutics is given to the method of empathy, which was developed by one of the ideologists of the cultural sciences W. Dilthey. However, the use of empathy as a method for understanding another person's soul, meanings and motives of the social action makes intuition precisely the basis of this method of understanding. And the question that arises before W. Dilthey about whether intuition can guarantee the objectivity and validity of the results of the cultural sciences by analogy with the natural sciences also appears in the methodology of M. Weber. Trying to get rid of psychologism and subjectivity of this method, but supporting the line of features of social methodology in contrast to the natural scientific method, Weber relies on the fact that a person is a conscious being. He comes to the conclusion that in order to explore the world of person's feelings, the logic of the formation of those concepts and meanings with which he operates needs to be studied. And certainly they are socially and culturally determined. Here, the criterion of the truth of cultural-historical concepts for Weber is "attribution to value". He strongly recommended distinguishing values from assessments asserting their diversity (moral values - good, aesthetic values - beauty, theoretical values truth, political values - justice, etc.). Values are universally valid, suprasubjective and absolute in the context of a specific cultural-historical era.

\section{Findings}

\section{Formation of social hermeneutics as a branch}

The basic works for the formation of social hermeneutics as a branch are the works of M. Weber, his theory of social action and understanding sociology. According to M. Weber, it is social reality that should be the subject of research. He believed that it was impossible to study social spheres outside people's activities. M. Weber writes: "An action is "social" if the acting individual takes account of the behaviour of others and is thereby oriented in its 
course" (Max Weber, 1990: 28). The most important idea of the thinker is the steady rationalization of all social life, which is a sign of its dynamic development.

Human behaviour is conscious and social reality requires not description but understanding, M. Weber emphasizes in his works. Unlike W. Dilthey, he closely links, not opposes, explanation and understanding. M. Weber emphasizes that it is the understanding of the meaning that the individual puts into his action that should interest the researcher (sociologist). The subjective meaning embedded in the social action by the individual correlates with behaviour of other people. The whole set of human actions gives rise to the emergence of stable semantic connections in society. They are culturally and historically determined. From the point of view of M. Weber, understanding takes place there where we have a purposeful action. That is, it is not a question of a "higher" "metaphysical" meaning or of an "objective" meaning that person's actions can gain regardless of his initial personal intentions. Here, M. Weber substantiates the idea of "understanding sociology", the purpose of which is to study actions deliberately performed by a person. In this case, to understand the meaning of the action means to understand the actor, and this means to understand the meaning of his action.

Further, analysing the possibility to use the empathy method for understanding social actions actively developed by W. Dilthey, M. Weber comes to a dialectical conclusion. On the one hand, using the empathy method and the power of imagination, believing that the researcher is able to understand the goals, values and errors of the individual insofar as they coincide with his own ones. In particular, if their cultural and historical horizons are close. But, on the other hand, the reliance of this method on intuition makes it too subjective and deprives the results obtained in this way of general validity. At the same time, the author writes: "The motives that this individual produces and those that he suppresses often mask the true connection of his actions so much that subjectively sincere evidence have only a relative value", and further "... people often feel contradictory, struggling impulses" (M. Weber, 1990: 6-2-633). These ideas are logically consistent with the basic ideas of psychoanalysis with regard to a strong influence of unconscious on human behaviour. The same actions can be carried out from a number of conflicting motives. In addition to this, person's motives pass through several filters: threshold of consciousness of the individual, filter of norms that does not allow communicating socially unacceptable motives, filter of verbalization and filter of the conceptual framework and experience of a particular individual. Moreover, the projections of one's own ideas, motives, one's own culturally and historically determined experience and life-purpose orientations of a researcher can greatly distort the results of a socio-hermeneutical procedure for understanding the motives of social actions. However, if the motives of actors may contain conflicting conscious and unconscious impulses, then in the end the social action itself is meaningful and purposeful.

As for the goals of the social action, the traditional action and the affective action of the four types of social actions proposed by M. Weber are on the verge of conscious and unconscious and, in a strict sense, they are not social actions. The goal-oriented rational action involves a clear awareness of the goal and meaning of the social action. And although all the presented types are closely related to culture, its elements are most clearly represented in the goal-oriented rational action. It is cultural norms and values (about duty, dignity, honour, beauty, etc.) that determine the social action of the individual, even to the detriment of own goals. Knowledge of these culturally determined norms and values that create the semantic field of the goal-oriented rational action is of great importance for the understanding procedure.

\section{Diversity of socio-cultural horizons as a problem for understanding}


The problem of understanding in social hermeneutics is closely related to the sociocultural conditionality of this process. The dialectic of the situation is that, on the one hand, to understand a social action, it is necessary to understand the historical and socio-cultural conditionality of the actor and researcher and to merge their cultural and historical horizons. And on the other hand, understanding is always contextual. If a social action is detached from its interpreter (researcher) in time, then the impossibility of reconstructing the context and the cultural and historical gap between the actor and the interpreter can cause semantic misunderstanding. Contextual cultural and historical conditionality of meanings is formed in communication and it is very important for understanding to find ways to overcome this barrier for the purpose of identifying motives, goals and meanings of social actions. Here, the determination of implicit meanings and hidden motives, which in fact are the true motives of a particular social action in contrast to explicit declared meanings and motives, is of absolute importance for social hermeneutics. The difficulty here lies in the need to reconstruct both the subjective life context of the actor or actors of the social action and the external and internal circumstances that precede the social action and affect it. This process of clarification of meanings is associated with the interpretation procedure.

When interpreting in social hermeneutics, it is necessary to identify the degree of influence of hidden and explicit meanings on motivation and their manifestation in the social action itself. Inter alia, the problem is in the cultural semantic conditionality of the actor and the interpreter of the social action, generated in the process of interpretation of a new meaning generated by the researcher of the social action. The emerging hermeneutical distance between the meanings of the actor and the interpreter of the social action requires understanding, and the process of overcoming this contradiction requires the fusion of socio-cultural and historical horizons of the actor and the interpreter.

Other thinkers continue to develop the ideas of M. Weber, for example, Z. Bauman supports his idea that human actions are meaningful and, therefore, require a special kind of research. Like many theorists of hermeneutics (M. Weber, W. Dilthey, A. Schutz and others), Z. Bauman argues that the methods and discoveries of hermeneutical research can be as objective as the methods and results of science. In case of the social science, the situation is much more complicated, because describing and explaining the laws of functioning and development of society and social institutions, the object of the scientific description is the reality of people, that is, social reality. According to Z. Bauman, it is truly unique because actors give meaning to their actions. The thinker emphasized that actors not only have motives, but - most importantly - set specific goals. It is the goals that explain the social actions of people. For this reason, they (actions) must not be explained but first of all understood, in contrast to spatial displacements of physical bodies or chemical reactions. "Rather, to explain a human action means to understand it: to grasp the meaning that the actor endows with it" [Z. Bauman, 1996: 215]. That is why understanding is the central category of social hermeneutics aimed at identifying the meanings, motives and goals of social actions. The natural world, which is the object of study of the natural sciences, is characterized by semantic neutrality, i.e. it is devoid of any human or suprahuman meanings (if we do not take into account religious approaches) in contrast to the human society permeated with meanings. And it is social hermeneutics that sets the task of understanding all this semantic diversity, actions of a symbolic nature through social actions and their motives. A social action is interwoven into the culture of a particular society and is determined by the processes taking place in it. It is possible to understand the meaning and motive of this type of action only taking into account its cultural component.

H.-G. Gadamer points out that understanding is culture-related to the historical context, which is of priority when interpreting the motives and goals of the action. He notes that any act of understanding is integrated in a specific tradition, bringing together the concepts of 
tradition and culture. One culture goes towards another one in the act of understanding, in the area of a single symbolic world created by a human.

\section{Conclusion}

The problems of understanding in social hermeneutics are related to the peculiarity of the object being studied, namely, to its cultural and historical dynamism. Understanding the meaning of the sign system is impossible outside the language system and the culture of a particular nation, and the social action of the individual is interwoven into the historical and cultural context of the society in which he lives (actor) or which he studies (interpreter).

Explication of the meanings and motives of the action is of great practical importance, since the correct understanding of social actions of other people underlies the success of further actions of the interpreter. The individual, committing actions, seeks to be understood by other people - that is why the tasks of social hermeneutics are of an applied nature. Social reality is filled with meanings and actions of other people, which a person needs to understand as a social being. The success of a social action depends on how other people - on whom it was oriented or whom it somehow affected -understood it.

The difficulties of social hermeneutics are associated with the difference in images of social realities of the creator (actor) and interpreter (researcher), their historical and cultural conditionality. Desobjectivation of sociocultural objects for the purpose of understanding the projective meanings invested in them initially requires a deep analysis of many historical, social and cultural facts and sociocultural contexts of actors and interpreters. It is the dialogue of cultures that underlies the process of understanding social actions in social hermeneutics.

\section{References}

1. Z. Bauman, Thinking Sociologically (Basil Blackwell, 1990).

2. Z. Bauman, Thinking Sociologically: Textbook, ed. by A.F. Filippov (Aspekt-Press, Moscow, 1996).

3. H. Blumer, Der metodologische Standort des Symbolischen Interaktionismus, Alltagswissen, Interaktion und gesellschaftliche Wirklichkeit. Bd 1.

4. A. Borisenkova, Sociological Review, Hermeneutical Projects in Sociology (as exemplified by the works of J. Habermas and P. Ricoeur), 6 (2), 2007.

5. E. Durkheim, Sociology. Its Subject, Method, Mission, Compilation, afterword and notes by A.B. Gofman (Kanon, Moscow, 1995).

6. H.-G. Gadamer, The Relevance of the Beautiful, Ed. by V.S. Malakhov (Iskusstvo, Moscow, 1991).

7. M. Heidegger, Being and Time (Respublika, Moscow, 1993).

8. A.N. Isakov, Social Reality and Methodological Paradigms of Modern Philosophy // http://anthropology.ru/ru/text/isakov/socialnaya-realnost-i-metodologicheskieparadigmy-sovremennoy-filosofii.

9. A.S. Kravets, Formation of Social Hermeneutics, Bulletin of VSU. Series: Philosophy, 1, (2012.)

10. G. Mead Geist, Identitat und Gesellschaft, Frankfurt am Main, (1973).

11. L.O. Pazina, Types of REALITY and Their Epistemological Status. (monograph) (Publishing House of DSTU, Rostov-on-Don, 2010). 
12. L.O. Pazina, Socialization and Inculturation in a Technogenic Society, The problem of a human in the modern philosophy of technology. Russian Scientific and Practical Conference Dedicated to the Memory of I.A. Negodaev (Rostov-on-Don, 29 March 2018): Materials and articles. Publishing House of DSTU, Rostov-on-Don. (2018).

13. A. Schutz, Selected Works: World Shining with Meaning (ROSSPEN, Moscow, 2004).

14. A.A. Shadrin, Hermeneutics of Meaning of Socio-Philosophical Discursiveness: monograph (Publishing House "Udmurtskiy Universitet", Izhevsk, 2009).

15. G.V Sorokin., T.I. Eroshenko, A.V. Fedoseenkov, A.V. Malyshev, Postmodern and Social Problems of Cities, Materials Science Forum, 931, (2018).

16. M. Weber, Selected works. (Moscow, 1990).

17. M. Weber, Basic Sociological Terms. Selected Works (Progress, Moscow, 1990).

18. M. Weber, About some categories of "understanding" sociology, Selected Works: The Protestant Ethic and the Spirit of Capitalism, Ed. by S.Y. Levit (ROSSPEN, Moscow, 2006). 